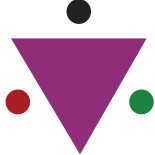 \\ IJCRR \\ Section: Healthcare \\ Sci. Journal Impact \\ Factor: 5.385 (2017) \\ ICV: 71.54 (2015) \\ Frontal Sinus Variability as a Tool in Forensic Identification- A Pilot Study Using Radiographic Images and Software Analysis
}

\section{Prachi Garhia ${ }^{1}$, Susmita Saxena ${ }^{2}$, Anunay Gupta ${ }^{3}$}

'BDS, ESIC Dental College and Hospital, Rohini, New Delhi; ${ }^{2}$ Professor and Head of Department, Department of Oral Pathology and Microbiology, ESIC Dental College and Hospital, Rohini, New Delhi; ${ }^{3}$ ntern, ESIC Dental College and Hospital, Rohini, New Delhi.

\section{ABSTRACT}

Aim: To evaluate the efficacy of the frontal sinus as an indicator for personal identification

Objectives:

1) To determine the presence or absence of symmetry of frontal sinus in each individual and draw comparison between males and females

2) To determine the number of lobes of frontal sinus in each individual and draw comparison between males and females

3) To determine the overall dimensions of frontal sinus in each individual and draw comparison between males and females

Materials and Methodology: Paranasal sinus view radiographs of sixty four volunteers visiting the hospital's outpatient department were randomly selected and the frontal sinuses were analysed using GIMP (GNU Image Manipulation Program) 2.0 software, based on Ribeiro Fde's measurement criteria.

Results: The overall dimensions of the frontal sinus were greater in males as compared to females, with statistically significant difference. Bilateral symmetry of frontal sinus was seen in 55 individuals, while asymmetry was observed in 9 individuals, out of which right dominant asymmetry was found in 6 individuals and 3 volunteers had left dominant frontal sinus. Twenty seven individuals showed less than or equal to four number of lobes, while thirty seven individuals had greater than or equal to five lobes. No cases of unilateral aplasia or complete aplasia were observed.

Conclusion: The frontal sinus displayed uniqueness in different individuals and can be used as a valuable aid in terms of personal identification.

Key Words: Forensics, Forensic dentistry, Paranasal sinus view

\section{INTRODUCTION}

Forensic dentistry is the sub specialty of dentistry that merges the science of dentistry with the subject of forensics to deal with matters pertaining to legal interest, be it cases of mass disasters or property related disputes. Forensic dentistry initially involved exploiting the uniqueness of the human dentition, dental restorations, and other intraoral details for identification purposes, but is slowly evolving into a more comprehensive and detailed practice. Fingerprint analysis, DNA profiling, anthropological methods, and other tech- niques can facilitate personal identification. ${ }^{1}$ However, in cases where the soft tissues of human remains have decomposed, or where DNA is damaged, fingerprint analysis or DNA identification does not seem to be of much use. In such a scenario, anthropological methods are preferred, of which comparative radiography forms a major part. ${ }^{2}$

Uniqueness of anatomical structures and specific variations in their morphology provide the foundation stone for forensic identification of unknown deceased persons. Among the four paranasal sinuses, namely, maxillary, frontal, ethmoidal,

\section{Corresponding Author:}

Prachi Garhia, BDS, ESIC Dental College and Hospital, Rohini, New Delhi.

Phone: +91-8851613659; Email: prachigarhia08@gmail.com

ISSN: 2231-2196 (Print)

Received: 21.03 .2019
ISSN: 0975-5241 (Online)

Revised: 06.04.2019
Accepted: 15.04 .2019 
and sphenoidal, frontal sinus has been a topic of significant forensic interest, owing to its unique presentation in each individual. ${ }^{3,4}$ Frontal sinuses are highly variable in size, ranging from a few cubic centimetres to almost the whole area of the frontal lobe, with an average height of $24.3 \mathrm{~mm}$ and an average extent of $29 \mathrm{~mm}$ from the midline to the lateral wall of the sinus. ${ }^{5}$ The significance of these sinuses in personal identification has time and again been emphasized by anatomists, radiologists, as well as anthropologists who have stated that no two frontal sinuses are alike. ${ }^{6}$ Studies have been done to utilize sinus radiography for the identification of remains ${ }^{7}$ as well as determination of sex and race. ${ }^{8}$ The current study was undertaken to study the frontal sinus variations in individuals and to propose its feasibility as a personal indicator in forensic dentistry.

\section{METHODOLOGY}

The current study was carried out in the Department of Oral Pathology and Microbiology, ESIC Dental College and Hospital, New Delhi, after acquiring clearance from the institute's ethical committee. Paranasal sinus view radiographs of sixty four volunteers visiting the hospital's outpatient department were randomly selected and evaluated. The sample comprised of thirty eight males and twenty six females within the range of twenty to fifty years, with no history of orthodontic treatment, maxillofacial surgery, trauma, endocrine disturbances, nutritional disorders or any marked facial asymmetry. The radiographs were taken by the same radiologist at $70 \mathrm{kVp}, 20 \mathrm{~mA}$, and an exposure time of 3 seconds. The radiographs were then observed and frontal sinuses were analysed by a single trained observer using the GIMP 2.0 software, with the help of radiographic tracings, based on the following criteria:

- Absence or presence of bilateral symmetry

- Number of lobulations, based on the indentations present on the sinus outline

- Greatest height of each frontal sinus

- Greatest width of each frontal sinus

In all the radiographs, the border lines of the frontal sinus were based on Ribeiro Fde's measurement criteria (Fig. 1). ${ }^{9}$ The reference lines and measurements used are as follows:

- Reference base line : a line passing through the superior border of orbit (A)

- Distance between the upper limit of the orbits and the highest point of the right frontal sinus (B)

- Distance between the upper limit of the orbits and the highest point of the left frontal sinus $(\mathrm{C})$

- Line marking the maximum lateral limit of the right frontal sinus (D)

- Distance between the lateral most boundary of the right frontal sinus and the line passing upwards along the nasal septum (E)
- Line marking the maximum lateral limit of the left frontal sinus $(\mathrm{F})$

Distance between the lateral most boundary of the left frontal sinus and the line passing upwards along the nasal septum (G)

\section{RESULTS}

The data was compiled using Microsoft Excel Spreadsheet and subjected to statistical analysis using Statistical Package of Social Sciences (SPSS).Version 20. Shapiro Wilk's test was done to determined normality of the data. Data was found to be normally distributed, thus parametric tests were done. Unpaired T-test was done to compare the height and width of the sinus among male and female groups. Chi square test was used to find out if there was any statistically significant difference in symmetry and number of lobes in the sinus of males and females.

The measurements of the study reveal that the overall dimensions of the frontal sinus were greater in males as compared to females. On applying the unpaired $t$ test for comparing the width and height of the sinuses in both the genders, the results were statistically significant ( $\mathrm{P}$ value $<0.05$ ). (Table 1 )

Bilateral symmetry of frontal sinus was seen in 55 individuals, i.e., 31 males and 24 females, while asymmetry was observed in 9 individuals ( 7 males and 2 females), out of which right dominant asymmetry was found in 6 individuals and 3 volunteers had left dominant frontal sinus. Chi square test was applied on the aforementioned data and the result between both the genders was not statistically significant ( $P$ value $>0.05)$. (Table 2 )

Twenty seven individuals showed less than or equal to four number of lobes, while 37 individuals had greater than or equal to five lobes. The results were statistically insignificant when Chi square test was applied to compare the number of lobes as recorded for both the genders. (P value $>0.05$ ) (Table 3) No cases of unilateral aplasia or complete aplasia were seen in the population under study.

\section{DISCUSSION}

The application of X-ray in the field of forensics was introduced by Professor Arthur Schuster in 1896, for demonstration of the presence of bullets inside a victim's head. ${ }^{10}$ Schüller was the first person to propose the utilization of the radiographic images of the frontal sinuses for the purpose of identification, while Culbert and Law were the first to describe the complete process of radiological identification using the pneumatic spaces found within the skull. $11,12,13$ 
The uniqueness of the anatomy of the frontal sinus makes it a helpful aid in forensic dentistry. These sinuses are considered similar to fingerprints, owing to the fact that each frontal sinus is distinctive and unique. ${ }^{2}$ There are various factors that make the frontal sinus a reliable indicator for personal identification:

- It is a highly variable anatomical structure, with even the frontal sinuses of monozygotic twins showing considerable difference 8

- It is considered to be relatively stable during the adult life until old age, when pneumatisation may occur owing to atrophic changes ${ }^{14}$

- It has strong surrounding walls and is found to be intact in human remains. Being posterior to the thick outer table of frontal bone further enhances its stability. ${ }^{15}$ It has been reported that approximately 800 1600 foot pounds of force is required to fracture the walls of the frontal sinus, as can be seen in victims of high impact accidents or gunshot injuries. ${ }^{16},{ }^{17}$

The morphology of the frontal sinuses remains practically unchanged during one's entire adult life, although some environmental factors can modify its structure, such as hyperpneumatization from sports activities, illnesses, infections, tumours or trauma, among others. It has been reported that the frontal sinuses are smaller and more scalloped in females. ${ }^{18,19}$ The results of the present study revealed that the dimensions of the frontal sinus are greater in males as compared to females, which seems to agree with the results of the studies carried out by Chaudhary and Singh, and Ponde et $a l .{ }^{1,18}$ Symmetry was seen in $85.9 \%$ of the cases under study, while the percentage of people with bilateral frontal sinus symmetry was comparatively lower in the study conducted by Chaudhary and Singh ${ }^{1}$, and David and Saxena ${ }^{10}$, with $62 \%$ and $58 \%$ of the individuals showing symmetry respectively. The results were significantly lower for the study conducted by Tang et al on Japanese population with only $43.1 \%$ showing bilateral symmetry. ${ }^{[19]}$ Asymmetry was observed in $14.1 \%$ of the patients, while it was reported to be $30 \%$ and $56.6 \%$ in the studies conducted by Chaudhary and Singh, and Tang et al respectively. ${ }^{1,19}$ No cases of sinus aplasia were observed in the present study, as opposed to Kullman who reported frontal sinus absence in $5 \%$ of the cases. ${ }^{20}$

The method used for frontal sinus analysis is quite easy and can be easily employed by a general dentist as well. Paranasal sinus view radiographs are quite commonly recorded for diagnostic purposes and require equipment that are generally available in a hospital set up, thus making its application quite feasible. Certain limitations related to the use of frontal sinus a tool for personal identification do exist. Frontal sinus has been reported to be affected by environmental as well as genetic factors. Growth hormone or somatotropin has also been stated to affect the sinus morphology. ${ }^{[6]}$ Errors may also occur due to slight differences in the radiographic technique used by different operators, which may be overcome by restricting the use to a single operator.

\section{CONCLUSION}

The study undertaken revealed that the frontal sinuses of the sixty four volunteers did not match and it was concluded that frontal sinus displayed uniqueness in different individuals and can be used as a valuable aid in terms of personal identification. The method used was very simple and can be easily applied by any general dental practitioner. The radiograph required for the study, i.e., paranasal sinus view, can be easily obtained. However, establishing the authenticity of the frontal sinus as a personal indicator requires further studies on larger samples, with the implementation of other parameters such as age.

\section{ACKNOWLEDGEMENTS}

Authors acknowledge the immense help received from the scholars whose articles are cited and included in references of this manuscript. The authors are grateful to authors / editors / publishers of all those articles, journals and books from where the literature for this article has been reviewed and discussed. The authors would also like to thank Dr. Roomani Srivastava, Tutor, Department of Public Health Dentistry, ESIC Dental College and Hospital, Rohini, New Delhi, for her inputs on statistical analysis.

\section{Ethical clearance}

Granted

\section{Patient consent:}

Taken

\section{Source of funding:}

None

\section{Conflict of interest:}

None

\section{REFERENCES}

1. Chaudhary S., Singh U., Uniqueness of Frontal Sinus as a Personal Identification in Forensic Odontology. Ann. Int. Med. Den. Res. 2016; 2(5):AT07-AT09

2. Divakar KP., Forensic Odontology: The New Dimension in Dental Analysis. Int J Biomed Sci. 2017;13(1):1-5.

3. Harris AM, Wood RE, Nortjé CJ, Thomas CJ. The frontal sinus: forensic fingerprint? A pilot study. The Journal of forensic odonto-stomatology. 1987 Jun;5(1):9-15.

4. Harris AM, Wood RE, Nortjé CJ, Thomas CJ. Gender and ethnic differences of the radiographic image of the frontal region. The 
Journal of forensic odonto-stomatology. 1987 Dec;5(2):51-7.

5. Donald PJ, Gluckmann JL, Rice DH. The Sinuses. New York: Raven Press; 1994. p.41-44

6. Nambiar P, Naidu MD, Subramaniam K., Anatomical variability of the frontal sinuses and their application in forensic identification. Clinical Anatomy: The Official Journal of the American Association of Clinical Anatomists and the British Association of Clinical Anatomists. 1999;12(1):16-9

7. Kanchan T, Krishan K, Menezes RG, Suresh BK, Lobo SW. Frontal sinus radiographs--a useful means of identification. Journal of Forensic and Legal Medicine. 2010 May;17(4):223-4.

8. Igbigbi PS, Nanono-igbigbi AM. Determination of sex and race from the subpubic angle in Ugandan subjects. The American journal of forensic medicine and pathology. 2003 Jun $1 ; 24(2): 168-72$.

9. Ribeiro Q, de Andrade F. Standardized measurements of radiographic films of the frontal sinuses: An aid to ENT: Ear, Nose \& Throat Journal. 2000 Jan 1;79(1).

10. Eckert, W.G. \& Garland N. History of the forensic applications in radiology. The American Journal of Forensic Medicine and Pathology.(1984). Vol. 5, No. 1, p. 53-56, ISSN:0195-7910

11. CULBERT WL, LAW FM. Identification by comparison of roentgenograms: of nasal accessory sinuses and mastoid processes. Journal of the American Medical Association. 1927 May $21 ; 88(21): 1634-6$.
12. Gruber J., Kameyama MM., The role of radiology in forensic dentistry. Pesquisa Odontológica Brasileira. 2001 Sep;15(3):263-8

13. Carvalho SPM, Silva RHA, Lopes Jr C, Sales-Peres A., Use of images for human identification in forensic dentistry. Radiol Bras. 2009;42(2):125-130.

14. Yoshino M, Miyasaka S, Sato H, Seta S. Classification system of frontal sinus patterns by radiography.Its application to identification of unknown skeletal remains. Forensic Science International. 1987 Aug 1;34(4):289-99.

15. Marlin DC, Clark MA, Standish SM. Identification of human remains by comparison of frontal sinus radiographs: a series of four cases. Journal of Forensic Science. 1991 Nov 1;36(6):176572.

16. Nahum AM. The biomechanics of maxillofacial trauma. Clinics in plastic surgery. 1975 Jan;2(1):59-64.

17. Wallis A, Donald PJ., Frontal sinus fractures: a review of 72 cases. The Laryngoscope. 1988 Jun;98(6):593-8.

18. Schuller A. A note on the identification of skulls by X-ray pictures of the frontal sinuses. Med J Aust. 1943 Jun 19;1:554-6.

19. Tang JP, Hu DY, Jiang FH, Yu XJ. Assessing forensic applications of the frontal sinus in a Chinese Han population. Forensic Science International. 2009 Jan 10;183(1-3):104-e1.

20. Kullman L, Eklund B, Grundin R. Value of the frontal sinus in identification of unknown persons. The Journal of forensic odonto-stomatology. 1990 Jun;8(1):3-10.

Table 1: Comparison of width and height of sinus of males and females

\begin{tabular}{llllcccc} 
Dimensions & Gender & N & Mean & $\begin{array}{c}\text { Standard } \\
\text { Deviation }\end{array}$ & $\begin{array}{c}\text { Confidence } \\
\text { Interval - Lower } \\
\text { Bound }\end{array}$ & $\begin{array}{c}\text { Confidence } \\
\text { Interval - } \\
\text { Upper Bound }\end{array}$ & $\begin{array}{c}\text { P-value } \\
\text { Mesiodistal width (Right) }\end{array}$ \\
in mm & MALE & 38 & 32.43 & 7.804 & 2.3023697 & 9.8429744 & o.oo2* $^{*}$ \\
Mesiodistal width (Left) & FEMALE & 26 & 26.36 & 6.787 & & & \\
in mm & MALE & 38 & 30.774 & 8.0609 & 1.4032029 & 9.7980116 & $0.010^{*}$ \\
Height (Right) in mm & FEMALE & 26 & 25.173 & 8.523 & & & \\
& MALE & 38 & 20.218 & 7.29 & -.2627929 & 6.4457888 & $0.070^{*}$ \\
Height (Left) in mm & FEMALE & 26 & 17.127 & 5.4 & & & \\
& MALE & 38 & 20.526 & 7.276 & 1.2515945 & 7.9933448 & $0.008^{*}$ \\
\hline
\end{tabular}

*Statistically significant

Table 2: Comparison of symmetry between male and female groups

\begin{tabular}{llccccc}
$\begin{array}{l}\text { Gender } \\
\text { Bilateral Symmetry } \\
\text { Right Dominant }\end{array}$ & Number & \multicolumn{2}{c}{$\begin{array}{c}\text { Symmetry } \\
\text { Left Dominant }\end{array}$} & Total & Pvalue \\
Male & $\%$ & 31 & 4 & 3 & 38 & 0.301 \\
Female & Number & $81.6 \%$ & $10.5 \%$ & $7.9 \%$ & $100.0 \%$ & \\
& $\%$ & 24 & 2 & 0 & 26 & \\
Total $\%$ & Number & $92.3 \%$ & $7.7 \%$ & $0.0 \%$ & $100.0 \%$ \\
& $85.9 \%$ & 55 & 6 & 3 & 64 \\
\hline
\end{tabular}


Table 3: Comparison of number of lobes between male and female groups

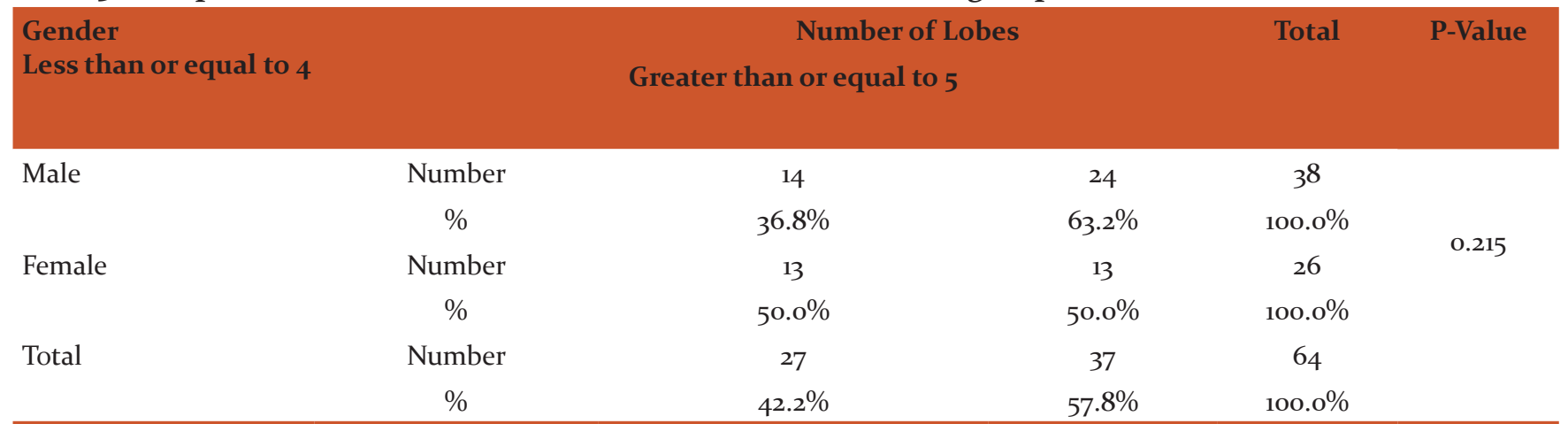

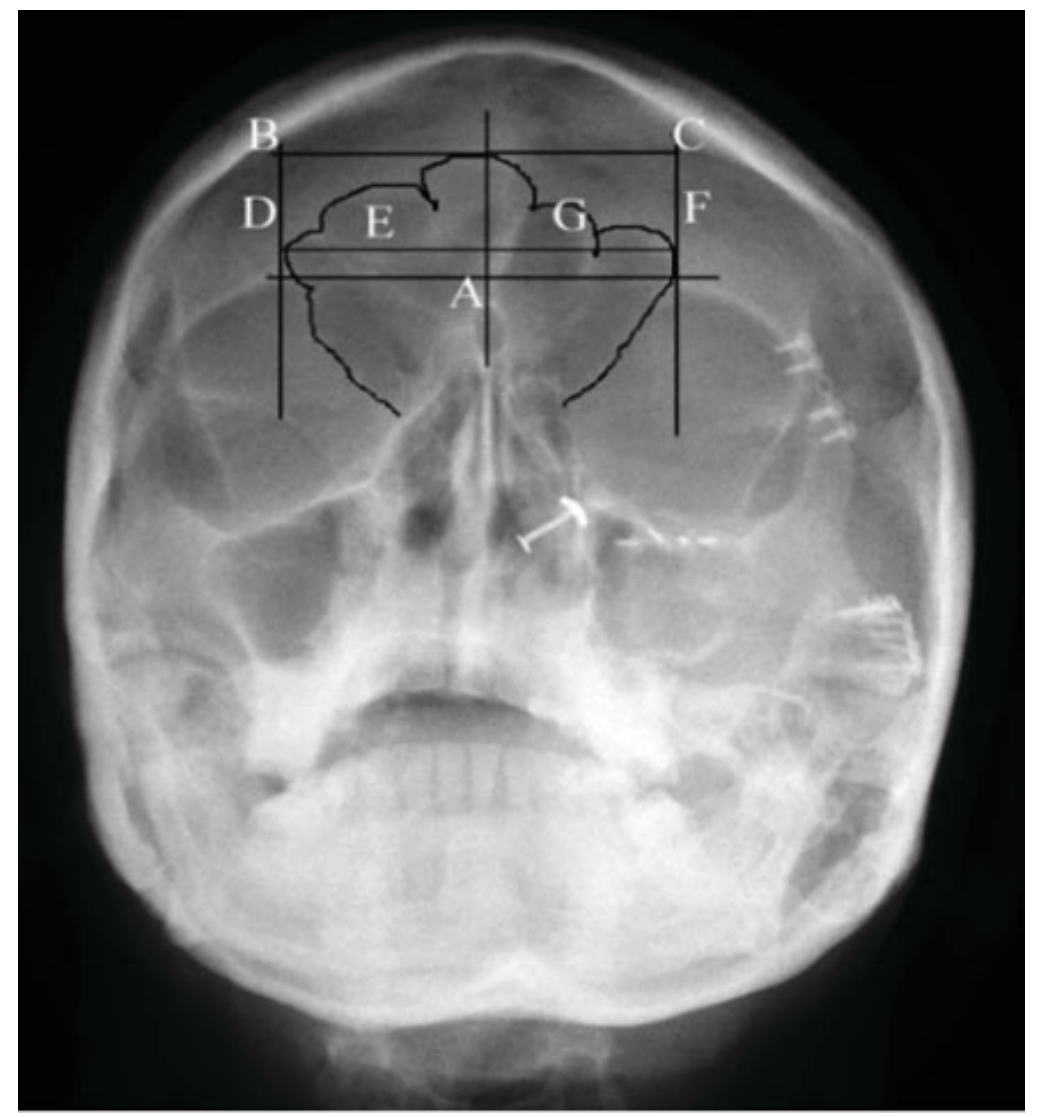

Figure 1: PNS View radiograph showing markings based on RibeiroFde's measurement criteria. 